\title{
«La princesa i el pèsol» (ATU 704): de les reescriptures escolars a la construcció identitària
}

\author{
Alexandre Bataller Català \\ Universitat de València \\ alexandre.bataller@uv.es
}

\begin{abstract}
RESUM
A partir del conte d'Andersen "La princesa i el pèsol», s'aborden qüestions que afecten el sentit $i$ difusió d'un text que forma part del cànon de contes clàssics, objecte de pràctiques discursives diverses. En primer lloc, la interpretació de la sensibilitat extrema de la seua protagonista i la reflexió sobre el possible missatge misògin del relat. En aquest sentit, es tracta la reescriptura dels contes de fades proposada per la crítica feminista i l'aparició de nous contes metaficcionals que dialoguen intertextualment amb els clàssics. S'hi aborda la presència i l'ús actual de la figura dels contes de princeses en l'àmbit escolar. En el context de la "glocalització", que dona visibilitat a les cultures locals, es tracta el tipus folklòric ATU 704 i el seu reflex en textos de la rondallística catalana, com és el cas de les «Tres al-lotes fines». Es mostra l'ús d'un relat folklòric com a element de la memòria col-lectiva, capaç de representar la identitat i memòria d'una col-lectivitat. La "Delicada de Gandia", l'heroïna llegendària valenciana de la hipersensibilitat, ha passat de caracteritzar una qualitat negativa a ser un simbol d'identitat local reivindicat per diverses vies.
\end{abstract}

PARAULES CLAU

«La princesa i el pèsol» (ATU 704); H. C. Andersen; reescriptura feminista del conte de fades; literatura infantil i juvenil; identitat col-lectiva

\begin{abstract}
Based on Andersen's story "The princess and the pea", this paper addresses questions that affect the meaning and dissemination of a text that is part of the canon of classical tales and the subject of various discursive analyses. First, we look at how the extreme sensitivity of the protagonist has been interpreted and reflect on the possible misogynistic message of the story. In this regard, we discuss the rewritings of fairy tales proposed by feminist criticism and the appearance of new metafictional stories that engage in an intertextual dialogue with the classics. We also address the presence and current use of tales involving the figure of the princess in schools today. In the context of "glocalization", which gives visibility to local cultures, we discuss tale type ATU 704 and Catalan versions of this folktale such as "Tres al-lotes fines". We show how folk tales are used as an element of collective memory capable of representing the identity. The "Delicada de Gandia", the hypersensitive legendary heroine in Valencian folk literature, has gone from characterizing a negative quality to becoming a symbol of several aspects of local identity.
\end{abstract}

KEYWORDS

"The princess and the pea" (ATU 704); H. C. Andersen; feminist rewriting of fairytales; children's and youth literature; collective identities

REBUT: 8/O2/2OI8 | ACCEPTAT: 9/04/2OI8

Estudis de Literatura Oral Popular, núm. 7, 20I8, 27-46 | DOI: Io.I7345/elop20I827-46

ISSN: 2OI4-7996 | http://revistes.urv.cat/index.php/elop 
1. «La princesa i el pèsol» d'Andersen i la interpretació de la hipersensibilitat

El cèlebre conte de Hans Christian Andersen «Prindsessen paa Ærten» va ser publicat el 8 de maig de I835, a Copenhaguen, per Carl Andreas Reitzel. El seu argument és ben conegut. Un príncep solter està obsessionat no només a casar-se amb una princesa, sinó que en vol una que siga vertadera. Després de molt buscar sense èxit, arriba al castell una jove que diu haver sobreviscut a un naufragi. La dona apareix enmig d'una nit de tempesta, amarada i amb un aspecte que, com salta a la vista, no és el d'una princesa. No obstant això, ella assegura que és una princesa veritable. La reben al castell i li preparen una habitació per passar la nit. La mare del príncep hereu col-loca un pèsol sota dels diversos matalassos amb els quals munten el llit (vegeu la icònica imatge a la figura I). Depenent de si nota o no la petita llavor mentre dorm, se sabrà si és una princesa vertadera, com ella assegura ser.

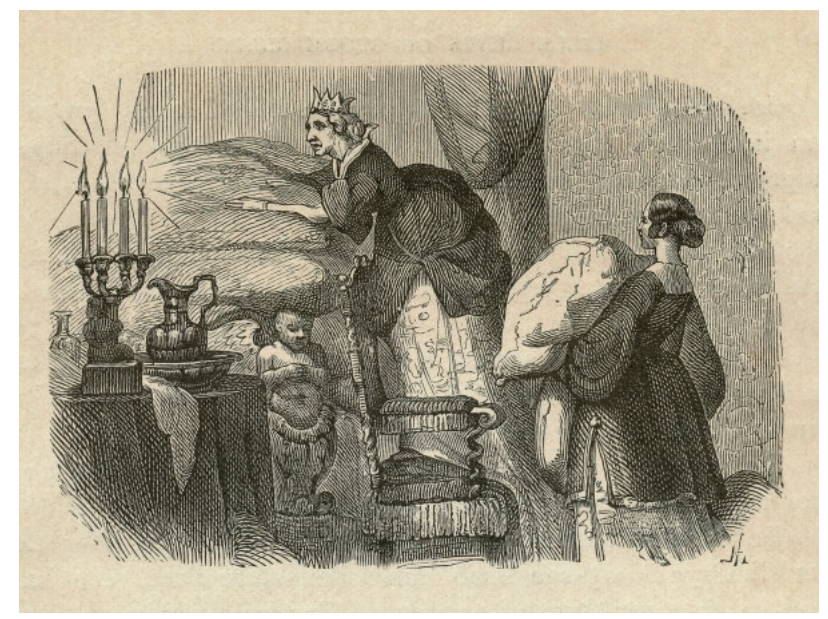

Figura I. Gravat de la ia edició (I835).

Des del mateix moment de la publicació, el conjunt de contes va rebre dures crítiques a Dinamarca i, en concret, del conte «La princesa del pèsol» ja se n'advertia la negativa associació entre la fragilitat femenina i la noblesa, com el mateix Andersen anotà en les seues memòries:

En el año I836 sólo la revista Dannora, dirigida por Johannes Nikolai Høst, traía una reseña, que ahora puede que resulte graciosa, pero que entonces me molestó mucho, como es natural. Dice que «estos cuentos podrían divertir a los niños, pero en nada contribuir a su formación, no atreviéndonos siquiera a asegurar que sean inofensivos. [...] El crítico considera que La princesa y el guisante no tiene ninguna gracia, que «no solo no es una historia poco delicada, sino verdaderamente nociva, ya que el niño puede sacar la conclusión que una dama noble tiene por fuerza que ser frágil». Al final se expresa el deseo de que el autor «deje de perder el tiempo escribiendo "cuentos infantiles"» (Andersen I989: 89-90). 
S'ha comentat que en el fons d'aquest relat es troba, segurament, l'episodi biogràfic de l'autor que no va ser acceptat per la burgesia danesa del seu temps (Wullschlager 2000: 290-29I). Tot i el seu reconeixement com a escriptor, Andersen va haver de plegar-se a les humiliacions dels cercles socials dominants, alhora que va desenvolupar un punt de vista àcid contra l'aristocràcia. En concret, en el conte «Prindsessen paa Ærten» l'escriptor danés es burla de les mesures «curioses i ridícules» assumides per la noblesa per establir el valor de les línies de sang (Zipes 2005: 35; Wullschlager 2000: I5I). La reivindicació d'una qualitat interior de les persones, més enllà del seu aspecte físic, podria evocar Heriette Wulff (I804-I858), dona contrafeta, de qui l'autor s'enamorà als vint anys (Mönninghoff 2005: I62-I63).

Des de la seua publicació, els contes d'Andersen han guanyat en acceptació social a mesura que els «adults themselves became more tolerant of fantasy literature and realized that it would not pervert the minds of their children» (Zipes 2000: XXvI). Les seues quatre col-leccions de contes, publicades entre I835 i I872 van ser les primeres a ser traduïdes del danés a altres llengües. Com s'ha assenyalat (Bravo-Villasante I998: I), Andersen pren el folklore danés per elaborar uns relats carregats d'ànima poètica. Una característica estilística que va ser reconeguda pels crítics del seu temps. Adam i Heidmann (2002) consideren que els seus contes subverteixen l'estil «èpiconarratiu i impersonal» dels germans Grimm i introdueixen una modalitat «subjectivolírica» que s'aparta de la tradició i de les convencions genèriques del conte popular. En el cas del conte que ens ocupa, els mateixos lingüistes suïssos qualifiquen els sofriments del príncep com una «malaltia semiològica». El príncep manifesta dificultats per entendre les convencions sociosimbòliques, està inquiet per les aparences, viu desconfiant dels signes verbals i no verbals. Per fi, la reina el lliurarà del seu maldecap mitjançant una estratificació que l'ajuda a discernir l'autèntic del fals, i això li permet casar-se amb una princesa autèntica que està «certificada». Aquest procés d'autenticació està tractat de manera irònica, com es manifesta en el fet que l'objecte utilitzat per a la prova del llit reial, el pèsol, està ben conservat al museu i que encara es pot contemplar si ningú no se l'ha emportat. El conte acaba amb el sintagma d'interpretació irònica «una història real» (en danés: «en rigtig Historié», en correspondència amb la «rigtig Prindsesse»).

No cal dir que la concepció moderna sobre el valor social dels individus entra en contradicció amb la idea de fons del conte d'Andersen, que relaciona la sensibilitat com un privilegi exclusiu de la noblesa. Podem dir que l'extrema sensibilitat de la princesa ha estat interpretada, al llarg del temps, en funció de l'associació cultural existent entre la fragilitat física i l'emocional atribuïda a les dones, que exigeixen un tractament especial (vegeu Tatar 2008: 70-77). Unes altres interpretacions del conte incideixen en la clau humorística o consideren que la sensibilitat de la princesa és una metàfora de la profunditat dels sentiments i de la compassió:

El tono informal y humorístico de esta historia sobre una princesa de una delicadeza patológica hacen más aceptables muchos aspectos que podrían herir la sensibilidad contemporánea. [...] Asimismo, Andersen nos ofrece una heroína atrevida, que desafía los elementos y se presenta en la puerta del príncipe, después de conseguir localizarlo (Tatar 2004: 298). 
El pèsol, l'objecte convertit en símbol, que acabarà en un museu, és l'element originador del desenllaç perquè la princesa «havia sentit la molèstia del pèsol»:

L'endemà li demanaren com havia dormit.

Oh! Terriblement! —digué la Princesa-. Amb prou feines he tancat els ulls en tota la nit! Déu sap què hi havia al llit! Hauria dit que jeia damunt alguna cosa dura, i tinc tot el cos blau i negre, aquest matí. És terrible!

Tot seguit veieren que devia ésser una princesa de bo de bo, quan havia sentit el pèsol a través de vint matalassos de llana i vint matalassos de ploma. Ningú sinó una princesa de bo de bo no podia tenir una pell tan delicada (Andersen I969: I55).

Fins al punt que la crítica feminista actual interprete la qualitat física de la princesa com una forma d'insatisfacció que definirà la seua vida i la impulsarà a actuar, com expressa l'escriptora i assagista feminista americana Vivian Gornick:

Ella no ha venido a buscar al príncipe sino al guisante. El momento en que siente el guisante bajo los veinte colchones es su momento. Éste es el verdadero sentido de su viaje, la razón por la que ha ido tan lejos, lo que ha venido a afirmar: la insatisfacción que la mantendrá viva (Gornick I998, citada per Tatar 2004: 300, n. 3).

\section{Reescriptura i reinterpretació metaficcional de «La princesa i el pèsol» en la literatura infantil $i$ juvenil actual}

La folklorista Jeana Jorgensen (2008) diferencia tres nivells en l'estudi del folklore des d'una perspectiva de gènere. El primer, un nivell textual, interessat en el contingut dels relats, els temes i els personatges principals que hi intervenen. El segon, un nivell contextual, centrat en les persones que fan de col-lectores o d'informants dels materials folklòrics. I, el tercer, un nivell metatextual, relacionat amb la manera en què la variable gènere incideix en l'adaptació dels textos o en l'elaboració de versions transgressores que capgiren els rols dels personatges respecte als rols tradicionals de gènere. En la seua panoràmica a la situació de la recerca en relació amb la literatura popular catalana des d'una perspectiva de gènere, Carme Oriol (2OI3) constata el creixement de treballs adscrits al nivell contextual, centrats en l'aportació de les dones com a transmissores i com a recol-lectores de literatura popular. En el nostre cas, fixarem l'atenció en els nivells textual i metatextual.

A partir de la dècada dels setanta del segle passat, la divisió entre els gèneres dels destinataris dels contes tradicionals fou objecte de discussió entre la incipient crítica feminista. Simone de Beauvoir havia obert el camí amb El segon sexe (I949), on incidia en la construcció de rols culturals i, en concret, posava l'exemple com els nens i les nenes aprenen a imitar els prínceps i princeses dels contes. De «La Bella Dorment», l'assagista francesa destacava una protagonista femenina que mostra «el fascinante prestigio de la belleza martirizada, abandonada y resignada» (Beauvoir I972: 37). La consideració misògina dels contes dels Grimm va donar pas als primers treballs interpretatius d'enfocament feminista, a partir de l'article de Lieberman (I972). Colette Dowling (I982) va definir el «complex de la Ventafocs» com la por de les dones a la independència, com un desig inconscient 
de ser ateses per altres, basant-se principalment en la por de ser independents. Aquest corrent feminista d'interpretació dels contes va donar com a resultat la florida de les reescriptures dels contes, una tendència que arriba fins els nostres dies. Un moviment crític, desenvolupat als Estats Units emmarcat en l'anàlisi de les adaptacions de Walt Disney. Les princeses dels contes impulsades per Disney, en concret, han configurat un determinat patró de la feminitat:

Who can imagine a fairy princess with hair that is anything but long and blonde, with eyes that are anything but blue, in clothes that are anything but a filmy drape of gossamer and gauze? The fairy princess remains one of the most powerful symbols of femininity the Western world has ever devised (Brownmiller I985: 67).

De fet, la construcció de l'imaginari popular contemporani, basat en els contes de Blancaneus, la Bella Dorment o la Ventafocs, deu molt a Walt Disney (Zipes I995: 2I). Una reducció de l'imaginari popular d'arrel tradicional que Karen Klugman (I995: IO03) ha anomenat «disneyficació», definit com «the application of simplified aesthetic, intellectual, or moral standards to a thing that has the potential for more complex and thought-provoking expression». En tot cas, l'elevació de la passivitat a la categoria d'atractiu femení és una qualitat desfasada avui en dia, per la qual cosa no resulta estrany que en les seues últimes adaptacions animades dels contes de fades la companyia Disney haja retratat protagonistes més actives i independents: Tiana, en The Princess and the Frog (2009), i Rapunzel en Tangled (20IO).

I, encara, en 2OII Jennifer L. Hartstein va popularitzar un assaig on es referia a la «síndrome de la princesa», un transtorn generat per l'impacte negatiu i perillós sobre els infants de certs contes i personatges de ficció. Les xiquetes receptores d'aquests contiguts, diu, acabaran pensant que han de seguir uns patrons de bellesa per trobar el «príncep blau». Com a contrapunt, podem adduir el criteri clàssic de Bruno Bettelheim, el qual afirmava que a partir dels cinc anys cap xiquet no creu que aquestes històries siguen reals: «Una chiquilla disfruta imaginando que es una princesa que vive en un castillo y elabora fantasías de que lo es, pero cuando su madre la llama para ir a comer, sabe que no es una princesa» (Bettelheim 2OI2: 9I).

Les reescriptures feministes dels contes de fades dels seixanta i setanta parteixen de la idea que ningú no viurà feliç per sempre si no canviem les condicions socials i econòmiques de les relacions més explotadores i opressives entre els sexes, races i classes socials. Des de la crítica feminista, Ruth MacDonald (I982, citada en Colomer 2000: 70-7I i Colomer-Olid 2009) va diferenciar les tres opcions que, tant autors com mediadors, disposen per defugir el model negatiu del folklore: $a$ ) presentar els contes inalterats i tractar les possibles conseqüències nocives per als nens en el comentari posterior a la seua lectura; $b$ ) reescriure els contes alterant els aspectes discriminatoris, i $c$ ) escriure altres contes emprant motius folklòrics per aconseguir la mateixa eficàcia literària sense els inconvenients educatius. Els partidaris de no adaptar els contes argumenten que una societat idíl.lica, amb una situació igualitària entre els sexes, no ha existit històricament (Tucker I98I).

En aquest context es troba la col-lecció italiana de títol programàtic «Dalla part delle bambine», dirigida per Adela Turín i traduïda per Lumen, que entre I975 i I980 va publicar més de vint títols. El seu objectiu consistia a denunciar 
la situació de la dona i reivindicar una reformulació dels rols socials i familiars, amb la introducció de prínceps somiadors i princeses que no es volen casar. Des d'aquest moment, ens resulten habituals les princeses solteres que no tenen intenció de casar-se, com La princesa enjogassada de Babette Cole (I998) o princeses transgressores com les que ens presenten Roald Dahl (I985) o William Steig (20I2). Ventafocs que escapen del rol de ser princesa d'un príncep que no les farà felices (López 2OII) o obres d'èxit amb títols ben cridaners i significatius com $\mathrm{Hi}$ ha res més avorrit que ser una princesa rosa? (Díaz 20IO) o Les princeses també es tiren pets (Brenman 2OII).

A hores d'ara, trobem reescriptures i revisions en els contes de fades, tant en versions literàries com cinematogràfiques o plàstiques. Per exemple, la pel·lícula Princesas (2005), de León de Aranoa, que funciona com un intertext de la Ventafocs, al·ludeix també a la relació intertextual amb el conte d'Andersen, quan un personatge afirma que les princeses són sers delicats «tan sensibles que notan la rotación de la tierra». Tiffin (2009) caracteritza les versions dels contes actuals a partir de sis trets: l'autoconsciència metaficcional i intertextual, la complexitat narrativa, el seu caràcter multivocal, l'ús de la paròdia i de la ironia i la fusió amb altres gèneres literaris. Els actuals contes de fades metaficcionals possibiliten atorgar un nou sentit al contingut cultural heretat sense que se'n perda el sentit original en cridar l'atenció del lector sobre les cites que fan a imatges i textos literaris precedents. Les adaptacions dirigides al públic infantil són, per principi, profundament intertextuals. Sempre es parteix d'un text primari (hipotext) que és modificat per fer-lo correspondre amb un nou context de recepció, del qual resulta un segon text (hipertext). En el moment actual, dins un context cultural globalitzat, que més endavant tractarem, els contes canònics de la tradició universal funcionen com una immensa xarxa de relacions intertextuals, on conviuen personatges i llocs en dimensions alternes, que es manifesten de determinades formes en diferents mitjans. Els contes de fades més coneguts, com ja coneixem, s'han reproduït en innombrables variants i han generat innombrables manifestacions verbals i no verbals (Joosen 2OII: IO).

Aquesta força de la presència intertextual en les versions dels contes actuals dona com a resultat que els joves lectors de les últimes generacions puguen conèixer abans que el conte clàssic d'Andersen, per exemple, l'adaptació animada de la sèrie de «Les tres bessones» (Company-Capdevila I996), on l'amor està per damunt de la condició de ser princesa («el Rei diu: “ja t’hi pots casar, és una princesa de debò", i el Príncep respon: "I encara que no ho fos"», Herraiz 2003: 4). El reconegut àlbum de Jon Scieszka i Lane Smith The Stinky Cheese Man i Other Stupid Tales (I992) subverteix en un text metaficcional l'autoritat textual a través del joc «with literary and cultural codes and conventions» (McCallum I996: 400).

En aquest àlbum es troba la versió titulada «The Princess and the Bowling Ball», en la qual, el príncep, després de tres anys sense que cap princesa no note el pèsol sota els matalassos, s'enamora d'una pretendent i col-loca una gran bola de bitlles sota els matalassos, perquè la puga notar (vegeu figura 2). D'aquesta manera, aconsegueix que els seus pares l'aproven, es casen i siguen feliços («encara que no molt honestament»). 
«La princesa i el pèsol» (ATU 704): de les reescriptures escolars a la construcció...

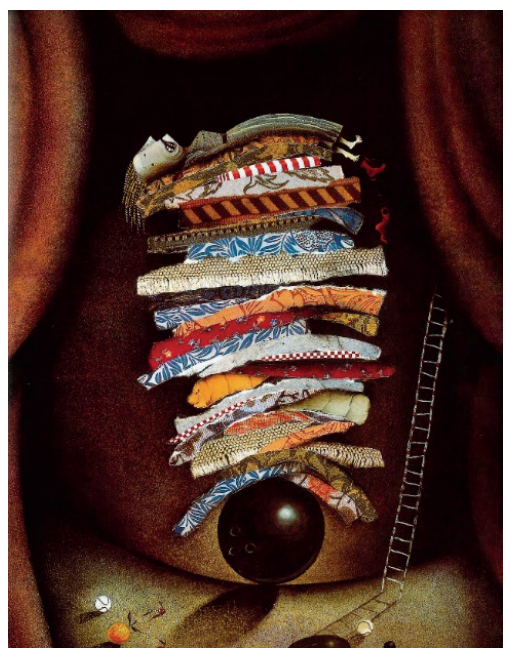

Figura 2. «The Princess and the Bowling Ball» (Scieszka I992).

D’alguna manera, totes aquestes relectures són expressió evident dels pressupòsits de Gianni Rodari (I973) basats en l'aplicació dels jocs fantàstics a les rondalles, equivocant o capgirant les històries, o, fins i tot, combinant-ne diverses, en una mena d' «amanida». Al lector se li deixa la funció activa de reconèixer els jocs textuals que hi ha darrere de cada escriptura. És el cas de les il-lustracions humorístiques del llibre d'imatges de l'anglesa Lauren Child (2005), que funciona com una mena de teatre en miniatura per on es mouen els personatges, en unes escenes plenes d'elements simbòlics: una princesa astuta (vegeu figura 3), un príncep bo o un puré de pèsols com a tancament del llibre.

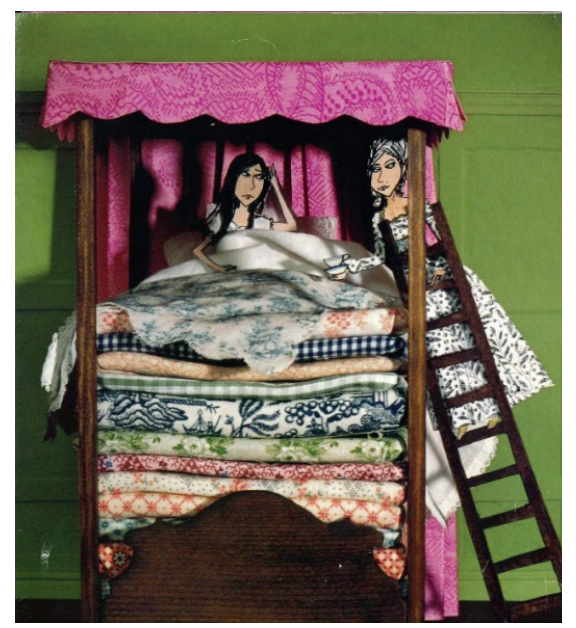

Figura 3. El despertar de la princesa (Child 2005). 
Una altra mostra d'aquest esperit transgressor és la versió de Bruce Lansky (2006), en la qual el príncep es nega a casar-se amb les princeses que no han pogut dormir durant tota la nit per tenir pèsols sota dels seus matalassos. Fins i tot, cal esmentar la versió de James Finn Garner, on la princesa és transgressora des de la correcció política:

cuando estaba ocupada en retirar todos los colchones sobrantes para compartirlos con algunos de los menos afortunados campesinos que habitan en torno al castillo, descubrí que bajo ellos había un guisante. Resulta increïble que en el estado en que se encuentra el mundo haya gente que desperdicie de ese modo la comida (Garner I996: 49).

En qualsevol cas, per activar el sentit i interpretació dels hipotextos que mostren les noves adaptacions, resulta necessari el coneixement de l'hipertext: «Es decir, una princesa activa e inteligente se sostiene literariamente activando la conciencia del lector de que las princesas son, como norma de referencia, hijas y prometidas pasivas de los auténticos protagonistas» (Colomer I994: I9).

Com acabem de mostrar, el vell relat d'Andersen és obert a versions contínues, com un referent intertextual que ha de ser reconegut pels joves lectors, noves lectures on apareix «el vell truc de princeses i pèsols» (Auch 2002). En tot cas, després d'una etapa de crítica social cap a allò «políticament correcte» i la confiança que els avanços igualitaris no podrien retrocedir, es detecten actualment estereotips sexistes que perviuen en la novel-la juvenil, que pot recuperar la imatge més conservadora de dona amb un vernís de falsa modernitat (Colomer-Olid 2009).

\section{Recepció del «La princesa i el pèsol» en l'àmbit escolar}

Com sabem, l'escola constitueix un agent de socialització en la formació d'identitats de gènere, tant dins el currículum manifest com dins l'anomenat currículum ocult, conformat per aquelles normes i valors implícits que no són qüestionats. El corpus de contes occidental s'ha transmés escolarment, en moltes ocasions, sense una necessària reflexió crítica:

All printed fairy tales are colored by the facts of the time and place in which they were recorded. For this reason, it is especially odd that we continue to read to our children - often without the slightest degree of critical reflection - unrevised versions of stories that are imbued with the values of a different time and place (Tatar I993: I9).

En aquesta línia, si considerem els contes com a instruments de socialització transmissors de pautes i models a seguir, encara trobaríem algunes veus, com la de la sociòloga Carmen Ruiz, que es mostrarien contràries a la lectura escolar dels contes clàssics:

¿cómo es posible que en el siglo xxi sigamos leyendo aún cuentos del XIx? Y más aún, ¿cómo es posible que en estos tiempos sigamos leyendo nuevas historias basadas en roles de género de otro siglo? La mayoría de los cuentos que se siguen leyendo y narrando han modificado sus diseños, sus ilustraciones, pero los valores, las pautas y los modelos siguen siendo los de antes: mujer princesa, guapa, cuidadosa y sumisa que espera a hombre príncipe, guapo, fuerte y guerrero (Ruiz 20I3: I9). 
Si ens fixem en el relat d'Andersen, el trobarem fàcilment fent part de materials didàctics i lectures en els nivells d'infantil i primària. Són freqüents les interpretacions superficials, que parteixen d'una simplificació reduccionista, que considera que la funció de la princesa protagonista incideix en les qualitats associades a la dona dependent: «la mujer, en este caso, la princesa, se caracteriza por su inhibición en todo el cuento anulando su razonamiento ante la prueba a la que es sometida» (Encabo-Hernández-Jerez 20I4: 3I7), caracteritzada per la seua «debilitat física i passivitat» i amb els atributs de «voluble i abnegada».

Un treball de camp realitzat per Alícia Santolària (20I5) el curs 20IO-II amb un grup de 13 mestres d'educació infantil i primer cicle d'educació primària d'un centre públic valencià de caire progressista, donà com a resultat l'establiment de tres grups de docents en atenció a les seues actuacions respecte als contes tradicionals protagonitzats per personatges femenins que manifesten una divisió de gèneres amb un possible rerefons sexista. Un primer grup de mestres considera que els contes perpetuen desigualtats socials, a més de ser masclistes. I, per tant, no els fan servir. Un segon grup afirma que els contes tradicionals no són aptes per als infants, perquè poden provocar trastorns psicològics en els nens, ja que parlen de la mort o manifesten relacions violentes. I, per tant, tampoc no els fan servir. I un tercer grup que reconeix que des del punt de vista de l'educació, la psicologia i l'estètica el relat folklòric es pot associar sense cap dificultat a la infància. I aquestes mestres sí que els fan servir.

Una opció, que hem tractat abans, consisteix a emprar les reescriptures feministes dels contes de fades. És l'opció que mostra el treball de camp de Bronwyn (I994) amb alumnes de preescolar d'escoles australianes, en el qual es demostra la construcció social del gènere. A The Paper Bag Princess (Munsch 1980), un dels textos emprats, és una princesa qui ha d'enfrontar-se al drac per salvar el príncep. La inversió de rols resulta una pràctica escolar habitual. A tall d'exemple, comprovem que la guia didàctica de l'obra teatral inspirada en el llibre de Díaz (20IO) proposa explicar la llegenda de Sant Jordi tot invertint els papers dels personatges.

Per apropar-nos als valors profunds del text, considerem oportú un primer acostament escolar a partir de la mirada humorística que Andersen impregna a la seua història, tal com proposa una contadora de contes, que, en els primers anys del segle xxı, aprofitava el context de les cases reials d'Espanya i Dinamarca, amb enllaços entre reis i princeses plebees com foren Letícia o Maria Elisabet, respectivament: «¿Son las princesas de ahora como las de antes? ¿Les habrán puesto a las consortes un guisante bajo veinte colchones para descubrir su idoneidad?» (García-Castellano 2005: 94-95).

Aquest punt de partida ens remet a la reflexió sobre els valors del conte, present en altres treballs didàctics: "com se sap que hom pertany a un col-lectiu o classe?, quins són els trets definitoris?», «quins criteris hi ha per distingir una cosa vertadera d'una de falsa?», «com distingir entre el que són les coses i les seues aparences o la distinció entre quines coses serien possibles i quines només probables en el conte» (Puig 20I5). El mateix cas trobem en el tractament dels valors del conte presents en una guia de lectura destinada a l'ensenyament primari (Bejarano 2OI5: 5), que defuig qualsevol debat o reflexió sobre l'hipotètic component sexista i aposta per cinc valors bàsics: «no deixar-se enganyar per les aparences», «quan menys t'ho esperes» (el que un més desitja apareix quan ja gairebé hem perdut l'esperança de trobar-ho), la «identitat» (la princesa reivindica el seu ori- 
gen), la «generositat» (els reis acullen la jove al seu palau, tot i que es tracta d'una desconeguda) i la «sinceritat» (la princesa no diu si ha trobat dur el llit fins que li ho pregunten). Finalment, la guia didàctica del capítol de les Tres Bessones «La princesa i el pèsol» tampoc no fa cap al-lusió al sexisme implícit, sinó que proposa uns altres dos temes: a) el tractament del racisme i la tolerància:

com determina el fet d'haver nascut en un lloc o en un altre, i si només aquest fet ens pot fer diferents, o si veritablement les diferències les creem nosaltres mateixos, pressuposant unes determinades característiques a una persona pel sol fet de pertànyer a un país o a un grup determinat. Es poden arribar a treballar temes de racisme i de tolerància (Herraiz 2003: 3).

i b) la reflexió sobre les idees preconcebudes sobre les persones:

Reflexionar entorn del fet d'intentar que, en cas de tenir alguna idea preconcebuda referida a una persona o a un grup de persones - tant sigui positiva com negativa-, ser-ne conscients de tenir-la i esforçar-nos per tal que aquesta idea no ens afecti en el moment de fer una nova coneixença, i deixar que sigui el dia a dia el que ens digui i ens demostri con és cadascuna de les persones amb les quals ens relacionem (Herraiz 2003: 5).

\section{El tipus narratiu folklòric ATU 704 i el seu reflex en la rondallística catalana}

És un fet que en la societat actual es puga accedir abans al coneixement del cànon internacional de contes, per la via de la «disneyficació» que ja hem tracat, que no pas tenir coneixença del repertori folklòric localitzat en un territori i compartit per les generacions que ens han precedit. És l'eterna qüestió de la relació entre la universalitat i particularitat de la rondalla, que també podem abordar en termes de «globalització» o «glocalització». Tot i que la globalizació es caracteritza per una tendència a l'homogeneització, a l'americanització cultural i cap a allò transnacional, també es defineix per l'exaltació d'allò local, en fer-ho visible. El global i el local són dues cares d'una mateixa moneda fins el punt que Robertson (I992) va encunyar el terme, aglutinador dels dos conceptes, de «glocalització». El professor americà Jack Zipes (2009), a partir de l'obra del sociòleg Zygmunt Bauman, reflexiona sobre el reflex de la «glocalització» en la producció de llibres per a infants. La transmissió dels contes pot ser global mentre siga un producte Disney, amb consorcis editorials i fílmics, però pot ser local quan una cultura s'ofereix com a alternativa a l'oficial o imposada. En aquesta dialèctica entre el global i el local, ens trobem una renovada presència de col-leccions amb antologies i reculls de contes populars (també en llibres anomenats «multiculturals»), que mostren que hi ha molta més varietat i riquesa folklòrica de la que presenta la cultura de masses. Sobre aquest fenomen, alguns teòrics han vist una expressió de la nostàlgia contemporània per l'aura de la tradició oral o, més pragmàticament, com una resposta a l'estandarització del mercat.

En el cas que ens ocupa, el conte d'Andersen eclipsa els altres relats procedents de les tradicions orals, tan propers com moltes vegades desconsiderats. Per a una interpretació exacta del motiu narratiu divulgat per Andersen és necessari el coneixement del tipus folklòric en què s'emmarca. En aquest cas el tipus, establert 
per Uther (2004), és l'ATU 704: The Princess and the Pea. A més de la versió d'Andersen, es recull una versió índia («The Three Delicate Wives of King Virtue-Banner: Which Is the Most Delicate?») i una altra localitzada al Tirol del Sud «Die Empfindlichste» (Schneller I867), on s'explica la història d'un príncep que comunica als seus pares que només es casarà amb la dona més sensible del món. Després de descartar-ne dues, amb qui finalment es casarà serà una a qui li ha caigut una flor de gesmil sobre el seu peu, el qual duia embenat a causa del dolor que li proporcionava. Històries semblants les trobem en la literatura grega. Sèneca el Jove (4 $\mathrm{aC}$ - 65) recull en el seu diàleg De ira el conte d'un sibarita anomenat Mindirides, de la ciutat de Síbaris, que es va queixar de sentir-se molt malament perquè havia dormit en un llit de roses i un dels pètals s'havia doblegat.

L'il-luminador i documentat treball de Christine Shojaei Kawan, amb molts exemples i referències, fa unes interessants precisions sobre les fonts orientals del relat i les variacions documentades en el context europeu. A més del motiu de la «hipersensibilitat» (ATU 704), distingeix dos motius més en el relat d'Andersen: el del «discerniment extraordinari» (AaTh 655: The Wise Brothers; AaTh 655A: The Strayed Camel and the Clever Deductions), també antic i d'origen oriental, i el de la «prova de la núvia». Aquest és tema freqüent en les narratives populars. La historiadora feminista alemanya Bea Lundt (I999) ha interpretat el conte com un ritual d'iniciació, com una història que demostra la importància de la funció reproductiva de la parella reial i com una prova de la disposició de la princesa a assumir aquesta tasca. El que es posa a prova en la candidata no és la seua sensibilitat, sinó la seua idoneïtat. Bea Lundt entén la prova del pèsol com una comunicació simbòlica per part de l'antiga reina que desitja preparar la seua nora per a futures dificultats. En aquest context de la prova, Shojaei (2005: IOI-IO2) esmenta el tipus nòrdic AaTh 545 The Cat Castle, en el qual una xica pobra, acompanyada d'un animal auxiliar, un gat o un gos, arriba a un castell on la reina mare li posarà proves, que pot tenir una correspondència en l'àmbit català amb ATU 4O2, en el qual el rei posa proves als fills, que, amb l'ajut d'un animal, hauran de cercar la donzella més bonica. L'excusa de la xica pel seu aspecte lamentable motivat pels efectes del vent i la pluja sembla, com explica Shojaei (2005: I06), un ressò de The Three Oranges (AaTh 408), un conte molt estés als països mediterranis i orientals, on una dona esclava negra se substitueix per l'heroïna, fingint que el sol, el vent, la rosada i la pluja l'han canviat, com en els versos del conte català «el sol i la serena / fan tornar la gent morena».

La versió d'Andersen ha eclipsat, també, la versió dels germans Grimm titulada «Die Erbsenprobe» (vegeu Uther 2008: 453-456), que va aparèixer publicada com el conte número I82 només en l'edició cinquena dels Drucke der Kinder- und Hausmärchen, de I843. Es va ometre en la següent edició de I850 per la seua similitud amb el relat d'Andersen. En aquesta versió és un rei qui ajuda el seu fill a trobar una princesa. L'anàlisi de Shojaei (2005) revela que els textos de Grimm i d'Andersen són prou diferents. Pel que fa a Andersen, sembla narrar una història bastant diferent del que ens proposa: una història «real» sobre una princesa «veritable» que és una mentida descarada. Si bé la versió dels Grimm ha estat considerada inferior a la d'Andersen, Adam i Heidmann han destacat les qualitats de la història dels Grimm, caracteritzada per la seua homogeneïtat narrativa i el seu caràcter emancipatori, gairebé feminista (Adam-Heidmann 2002: 156, I73; Adam 2OOI: 439-44I). 
Dins l'àmbit lingüístic català, trobem la rondalla mallorquina recollida a Manacor per Antoni M. Alcover (I9I3) «Tres al-lotes fines», la qual explica el relat d'un rei que tenia tres filles, belles però delicades. A la primera d'elles, un pètal de rosa li va caure damunt del cap, va caure esmorteïda a terra i pel trenc que li va obrir al cap ja mai més no va tornar a ser la mateixa («Li miren què tenia i li troben un grandiós trenc an es cap. L'hi havia fet sa fulla de sa rosa amb sa força que duia com queia»). Les seues germanes corregueren una sort semblant: la segona a causa d'una «rua» al llençol que li causa una terrible inflor i la darerra, pel constipat causat pel vol d'un mosquit, tot i estar protegida per set cristalls. La rondalla acaba amb una fórmula («Quina de totes tres ho era més? A veure qui ho endevina!») que presenta un ressò oriental (Shojaei 2005: 93). El conte ha donat peu a una cançó amb el mateix títol, amb lletra de Gabriel Janer Manila, editada per Maria del Mar Bonet al disc Bon viatge faci la cadernera (1990): «L'airet del capvespre / esfullà una rosa. / Vengué a caure un pètal / al cap de l'al·lota. / Per què eren tan fines? / I li feu un trenc. / Ai, quina passada! / Un trenc a la closca / tendra i delicada». La cantant mallorquina ha explicat l'estima que sent per la història perquè, com era habitual en el context mallorquí, sa mare li contava aquesta rondalla quan estava malalta i li feia un advertiment: «meam si seràs com una de ses tres al-lotes fines».

Durant les primeres dècades del segle xx, Joan Amades es va dedicar a recopilar i posar per escrit centenars de contes del folklore popular català. Una d'aquestes històries, recollida a Barcelona el I922, es titula «Les tres princeses fleumes» i presenta un argument similar: «Vet aquí que el rei Butxaques tenia tres filles tan pocacosa i tan fleumes que la claror d'una candela les enlluernava, que el soroll del respirar les eixordava i l'olor del pa les marejava» (Amades I950: 706). Fins i tot, la versió recollida a la població murciana de Mula és la clàssica de les tres princeses (Hernández 2009: 85-86).

\section{Reivindicació identitària de la sensibilitat extrema: la «Delicada de Gandia»}

La constitució d'una memòria col-lectiva és un element indispensable en la producció i reproducció d'una identitat comunitària. Com s'ha assenyalat, el folklore desenvolupa una tasca social de «màquina coinventora d'identitats»: «El folklore serviría, fundamentalmente, como archivo fácilmente manipulable desde el que construir —o reconstruir— las señas de identidad» (Díaz I996: I62). Per al sociòleg Maurice Halbawchs (I950), la memòria col-lectiva s'oposa a la memòria històrica, restringida a l'entorn temporal d'una generació, i a la qual reconeix una funció de reproducció de la tradició i de la identitat. Tal com ha estat definida per Pierre Nora (I988), la memòria col-lectiva es «el recuerdo o conjunto de recuerdos, conscientes o no, de una experiencia vivida y/o mitificada por una colectividad viva, de cuya identidad forma parte integrante el sentimiento del pasado». La tradició és memòria col-lectiva que recorre els temps i emmagatzema i conserva allò amb què un poble s'identifica, i és també la capacitat d'interpretar què és rellevant, significatiu i, per tant, inalterable en un poble. Els components de la memòria collectiva en forma de narracions, costums i cerimònies són utilitzats com a codis de significació variable (Homobono I990). Un esdeveniment memorial o festiu significatiu de la història o el folklore local pot adquirir protagonisme en el pre- 
sent com a suport de noves representacions de la identitat local en el context de la modernitat tardana, sense excloure la creació de recursos turístics i el seu consum.

Tot i que habitualment no s'haja relacionat la llegenda de la Delicada de Gandia amb el motiu de la hipersensibilitat del tipus ATU 704, nosaltres hem proposat aquesta identificació (Bataller 20I6). Quan d'algú es diu que «sembla la Delicà de Gandia», pensem en una persona fràgil, aprensiva, queixosa, objecte de molts accidents banals. L'expressió i la seua interpretació llegendària són vives dins i fora del territori valencià. La flor que va matar la «Delicada», com explica una interpretació que dona versemblança a l'accident, va ser una flor de pedra caiguda de la Col-legiata de Gandia. Una d'aquestes flors havia caigut, amb tan mala sort que ho va fer sobre una jove que anava als oficis, fins al punt de provocar-li la mort (Garcia Frasquet 2000: IOO-IO9; 20I7). De la sàtira de l'amanerament ciutadà de les dones gandianes s'arribarà a la construcció d'un relat: «convindria no oblidar el caràcter burlesc de la dita originària, que ha evolucionat en una llegenda edulcorada i melangiosa» (Garcia Frasquet 20I7: 23). El personatge apareix documentat per primera vegada dins la Rondalla de rondalles de Lluís Galiana del segle XviII. El pare Francesc Vidal i Micó (I735) ressenya el miracle de sant Vicent de I4I3. Durant una predicació es desprengué d'una teulada d'una casa una gran pedra que colpí el cap de na Joana de Prades, germana de la reina Margarida, segona muller de Martí l'Humà. La infanta hi havia acudit amb el cabell cobert de perles, diamants i robins, i Déu volgué reprendre-li la fatuïtat.

Per copsar el canvi de percepció social operat amb aquest personatge, ens detindrem en la pintura de I9I6 que Antoni Fillol dedica a aquest personatge (vegeu figura 4). Els crítics hi veuen un personatge enigmàtic i pertorbador. Una dona malaltissa, recelosa, inquietant i desagradable, alimentada per les mateixes obsessions, amb un pot a la mà com un beuratge que és una al-legoria de la seua malaltia. Les arrugues del front i els llavis accentuen la inquietud del seu rostre i la sensació de tristesa, el temor i la por, potser a la malaltia. (Pérez-Alcaide 20I5).

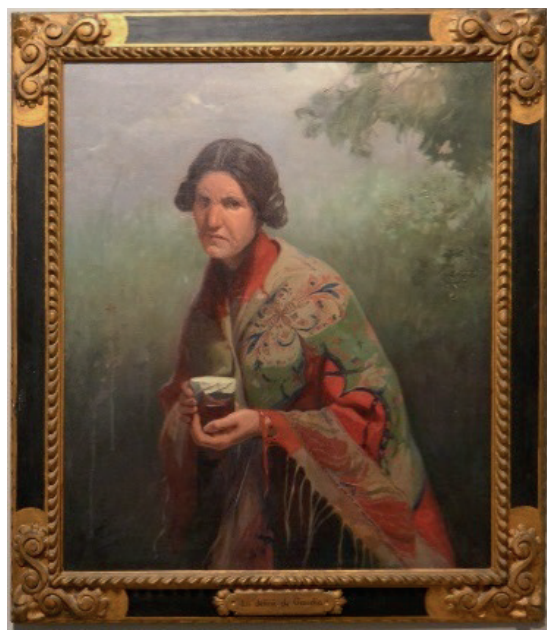

Figura 4. La «Delicada de Gandia» d’Antoni Fillol (I9I6). 
Emili Fornet estrenà al teatre Alkázar de València, el I93I, l'obra teatral La Delicada de Gandia, la qual gaudí d'un gran èxit aleshores. La delicadesa apareix descrita com una condició intrínseca de la persona, més que no pas una qualitat apresa: «Li diu: La Delicada de Gandia. / Com si això es deprenguera en un día! / Jo vullc ser delicat... i no puc!» (Fornet I932). Encara que no siga un relat sorgit d'un fet històric documentat, el motiu de la «Delicada de Gandia» ha gaudit d'una difusió excepcional fins arribar als nostres dies, amb llibres mongràfics (Climent I99I), o amb versos dedicats pel mateix Vicent Andrés Estellés (Garcia Frasquet 2000). El relat fa ja part del cànon de llegendes valencianes (Franco 20I5) i, a més, ha servit de rerefons a un recent llibre juvenil en el qual uns protagonistes joves indaguen en el personatge llegendari (Llorca 20I7), amb una clara vocació d'incidència en la construcció d'una identitat local per la via del referent folklòric.

En paral-lel a aquesta recuperació de la memòria per la via literària, en els últims anys, la delicadesa s'ha convertit en un referent identitari que assenyala i aglutina els gandians: des d'un pasdoble, compost per Joaquim Vidal i editat el I987 per la Unió Musical Sant Francesc de Borja de Gandia, fins al nom d'un carrer cèntric a la ciutat des del 2000 (vegeu figura 5), el nom d'algun comerç, la designació d'una cervesa artesanal, o el nom d'un dolç creat el 20I4 per l'Associació de Pastissers i Forners de Gandia. Unes evidències que emmarquem dins el context sociològic de recuperació de les tradicions perdudes que fou definit per Josep Martí (I996) com a «folklorisme».

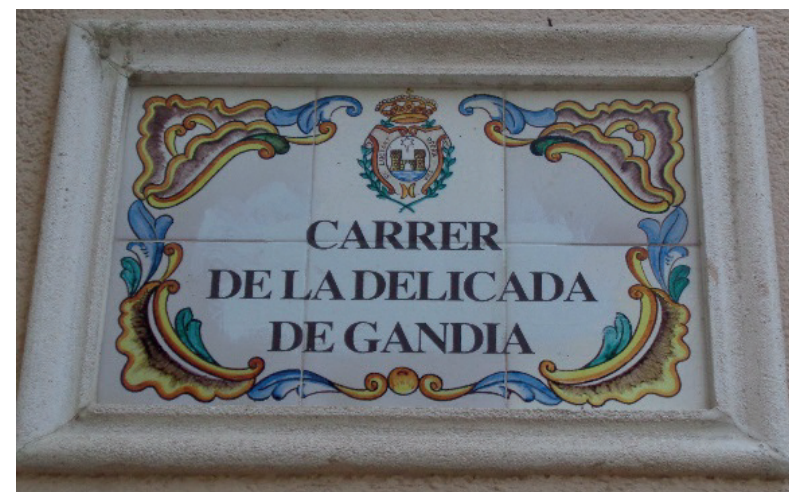

Figura 5. Placa del carrer de la Delicada de Gandia.

També les festes locals de les falles incorporen el nom de «la Delicà» a una falla «popular i combativa» i el de «gesmil» a una condecoració festiva. Un personatge de llegenda esdevé, doncs, una marca territorial, que es divulga amb fins comercials i turístics. S'hi reivindica una memòria i identitat col-lectives a partir de la posada en valor d'un personatge llegendari, símbol de la polidesa dels gandians en contrast amb la dels pobles de comarca.

En els últims anys, el reeixit joc de cartes, nascut el 2013, La fallera calavera ha donat pas a un llibre amb el mateix nom (Aguilar 20I5). Amb una estètica cinematogràfica, deutora de Tim Burton, l'heroïna valenciana de la hipersensibilitat es transmuta en un zombi que troba una especial complicitat amb una ressuscitada fallera morta que busca restablir la justícia i la veritat entre polítics arrogants. 
L'autor barreja esperpent i crítica social, vorejant el sarcasme, amb una desfilada de símbols (la paella, l'orxata, etc.) i de personatges identitaris valencians (la Delicà de Gandia i el mateix rei En Jaume en versió zombi).

Tot plegat ens obliga a considerar que, en el moment actual, la reivindicació positiva de la finor i la delicadesa extrema d'aquest personatge femení no és ja un model social del qual cal allunyar-se, sinó que cobra un protagonisme reivindicatiu positiu, impulsat per sectors socials progressistes i acceptat a hores d'ara, sense cap ombra de rebuig, per l'imaginari col-lectiu d'una ciutat i d'un poble.

\section{Conclusions}

De l'anàlisi del conte d'Andersen i, per extensió, del tipus ATU 704, en diferents contextos de difusió i recepció social i escolar, n'extraiem les conclusions següents:

El conte d'Andersen «Prindsessen paa Ærten» (I835) ha rebut històricament crítiques per l'associació entre fragilitat i condició femenina. Unes altres interpretacions en fan una lectura en clau humorística o entenen la sensibilitat de la princesa protagonista en clau metafòrica, en al·lusió als seus sentiments.

El corrent d'interpretació feminista dels contes de fades (aclaparats per un procés de «disneyficació»), aparegut en la dècada dels setanta del segle passat, impulsà l'aparició de reescriptures dels contes, que modificaven els aspectes discriminatoris i reformulaven els rols socials i familiars dels personatges, com ara la irrupció de contes protagonitzats per princeses transgresores.

Les adaptacions dels contes dirigides al públic infantil, en proposar lectures metaficcionals, funcionen com una xarxa de relacions intertextuals. Àlbums illustrats (Scieszka I992; Child 2005), contes per a infants (Lensky 2006) i adults (Garner I996) o adaptacions animades (Company-Capdevila I996) són una mostra de subversió, ironia o humor a partir de l'hipotext original.

A partir de l'anàlisi de treballs i propostes didàctiques per a un àmbit escolar, centrats en el conte d'Andersen, hem constatat que persisteixen interpretacions de l'actitud de la protagonista femenina del conte sobre la base de la seua debilitat física i passivitat, per la qual cosa es prefereixen adaptacions amb reescrptures feministes. Per contra, són presents unes noves visions centrades en la lectura del conte a partir d'uns altres valors: les aparences, la identitat, la tolerància o les idees preconcebudes.

La relació entre el global i el local, entre la «globalització» i la «glocalització», ens obri la porta a l'anàlisi i valoració de les fonts i variants del tipus ATU 704, al qual pertany el conte d'Andersen, en especial les emmarcades dins l'àmbit català («Tres al-lotes fines» $\mathrm{i}$ «Les tres princeses fleumes»).

L'anàlisi de la llegenda de «La Delicada de Gandia» en relació amb el tipus ATU 704 i a la seua eclosió en contextos socials i culturals recents, dins l'àmbit local i valencià, ens confirma la funció que els textos etnopoètics, adaptats a les noves sensibilitats socials, poden desenvolupar en la construcció d'una memòria i identitat col-lectives. 


\section{Referències bibliogràfiques}

ADAM, Jean-Michel (200I): «Textualité et transtextualité d'un conte d'Andersen: La princesse sur le petit pois». Poétique núm. I28: 42I-445.

ADAM, Jean-Michel; Ute HEIDMANN (2002): «Réarranger des motifs, c'est changer le sens. Princesses et petits pois chez Andersen et Grimm». Dins A. Petitat (éd.): Contes: l'universel et le singulier. Lausanne: Payot, p. I5--I74.

Aguilar, Enric (20I5): La fallera calavera. Il. d'Esther Méndez. Carcaixent: Sembra.

Alcover, Antoni M. (I9I3): Aplec de Rondaies Mallorquines de Jordi d'es Racó, vol. VI. Ciutat de Mallorca: Estampa d'En Sebàstia Pizà.

AmAdes, Joan (I950): Folklore de Catalunya: Rondallística (Rondalles-Tradicions-Llegendes). Barcelona: Selecta.

Andersen, Hans Christian (I835): «Prindsessen paa Ærten». Eventyr, fortalte for Børn. Copenhague: C. A. Reitzel.

- (I969): Rondalles de Hans Andersen. Trad. Josep CARner i Marià MANENT. Barcelona: Joventut.

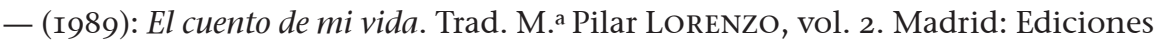
de la Torre.

Auch, Mary Jane (2002): The Princess and the Pizza. New York: Holiday House.

BATALLER, Alexandre (20I6): «Hipersensibilidad femenina, relato folklórico y literatura infantil: "La princesa y el guisante" (ATU 704)». Miríada Hispánica núm. I3: 99-II4.

Beauvoir, Simone (I972): El segundo sexo. Trad. Pablo Palant. Buenos Aires: Siglo Veinte.

BeJARANO, Beatriz (20I5): Proyecto de lectura «La princesa y el guisante. Hans Christian Andersen». Madrid: Anaya <http://www.anayainfantilyjuvenil.com/pdf/ proyectos_lectura/IJoo47980I_9999975380.pdf> [data de consulta: abril de 20I8].

Bettelheim, Bruno (20I2): Psicoanálisis de los cuentos de hadas. Trad. Silvia Furió. Barcelona: Crítica.

BONET, Maria del Mar (I990): Bon viatge faci la cadernera [enregistrament sonor]. Madrid: BMG Ariola.

BRAVO-VILLASANTE, Carmen (I988): Historia y antología de la literatura infantil universal, vol. I. Valladolid: Miñón.

Brenman, Ilan (2OII): Les Princeses també es tiren pets. Trad. Josep Franco. Alzira: Bromera.

BRONWYN, Davies (I994): Sapos y culebras y cuentos feministas. Los niños de preescolar y el género. Madrid/València: Cátedra / Universitat de València.

Brownmiller, Susan (1985): Femininity. New York: Ballantine.

CHILD, Lauren (2005): La princesa i el pèsol: en miniatura. Fotos Polly BorLAND, trad. Esther Rubio. Barcelona: Serres.

Climent, Joan (I99I): La delicà de Gandia: documental d'una llegenda. Oliva: Colomar. 
«La princesa i el pèsol» (ATU 704): de les reescriptures escolars a la construcció...

Cole, Babette (I988): La princesa enjogassada. Trad. Eudald EsCALA. Barcelona: Destino.

COLOMER, Teresa (I994): «A favor de las niñas. El sexismo en la literatura infantil». CLIJ núm. 57: 7-24.

- (2000): «La formació i renovació de l'imaginari cultural: l'exemple de la Caputxeta Vermella». Dins Gemma LuUch (ed.): De la narrativa oral a la literatura per a infants. Alzira: Bromera, p. 55-94.

COlOMER, Teresa; Isabel Olid (2000): «Princesitas con tatuaje: las nuevas caras del sexismo en la ficción juvenil». Revista Textos. Didáctica de la Lengua y de la Literatura núm. 5I: 55-67.

Company, Mercé; Roser CAPdevila (I996): La Princesa i el pèsol. Barcelona: Cromosoma/Televisió de Catalunya.

DAHL, Roald (I985): Cuentos en verso para niños perversos. Il. de Quentin BLAKE, trad. Miguel Azaola. Madrid: Altea.

DíAZ, Luis (I996): «En torno a la cultura popular y los conceptos de cultura: contribuciones a un debate permanente». Revista de dialectología y tradiciones populares núm. 5I (I): I59-I8O.

DÍAZ, Raquel (20IO): Hi ha res més avorrit que ésser una princesa rosa? Barcelona: Thule.

Dowling, Colette (I982): The Cinderella complex: women's hidden fear of independence. London: Fontana Paperbacks.

ENCABO, Eduardo; Lourdes HeRnÁNDEZ; Isabel JeREZ (2OI4): «Cuentos clásicos y estereotipos de género. Análisis de las narraciones inspiradoras de los textos que se usan en educación infantil y educación primaria». Dins J. I. Alonso; C. J. GómEZ; T. IzQUIERDo (eds.): La formación del profesorado en educación infantil y educación primaria. Murcia: Universidad de Murcia, p. 3I5-326.

FORNET, Emili (I932): La delicada de Gandía: comèdia en dos actes i en vers. València: Carceller.

FrANCO, Josep (20I5): Llegendes valencianes. Alzira: Bromera.

GARCIA FRASQUET, Gabriel (2000): Literatura i societat a la comarca de la Safor (I833-I936). València/Barcelona: Institut Interuniversitari de Filologia/Publicacions de l'Abadia de Montserrat.

— (20I7): «Gandia, València la Xica: pixavins i delicades». Dins Actes de la X Jornada d'Onomàstica. València: AVL, p. II-26.

García-Castellano, Ana (2005): "Contar Andersen en el aula». Dins Jaime GARCía (ed.): Andersen, "Ala de cisne»: actualización de un mito (I805-2005). Madrid: Ministerio de Educación y Ciencia, p. 87-Ior.

GARner, James Finn (I996): Más cuentos infantiles politicamente correctos. Trad. Gian CASTELli GAIR. Barcelona: Circe.

GORNICK, Vivian (I998): «Taking a long hard look at "The princess and the pea"». Dins Kate BERNHEIMER (ed.): Mirror, mirror on the wall: women writers explore their favorite fairy. New York: Anchor, p. I58-I67.

HalbWACHS, Maurice (I950): La Mémoire collective. Paris: Presses Universitaies de France. 
HARTSTEIN, Jennifer L. (2OII): Princess recovery: a how-to guide to raising strong, empowered girls who can create their own happily ever afters. Adams Media Corporation.

HeRnÁndez, Ángel (2009): Las voces de la memoria. Cuentos populares de la Región de Murcia. Guadalajara: Palabras del Candil.

Herraiz, Cristina (2003): Guia didàctica Les Tres Bessones. La princesa i el pèsol. Barcelona: Generalitat de Catalunya.

НомовоNO, José Ignacio (I990): «Fiesta, tradición e identidad local». Cuadernos de etnología y etnografía de Navarra núm. 55: 43-58.

JoOSEN, Vanessa (2OII): Critical and creative perspectives on fairy tales: an intertextual dialogue between fairy-tale scholarship and postmodern retellings. Detroit: Wayne State University Press.

Jorgensen, Jeana (2008): «Gender». Dins Donald HAASE (ed.): The Greenwood Encyclopedia of Folktales \& Fairy Tales. Connecticut/London: Greenwood Press, p. 402-404.

KLUGMAN, Karen (1995): Inside the mouse: work and play in Disney world. Durham: Duke University Press.

LANSKy, Bruce (2006): El príncipe que dio calabazas a Cenicienta. Trad. Ana PÉREz. Barcelona: Obelisco.

LEÓn DE AranoA, Fernando (dir.) (2005): Princesas. Espanya: IFC Films.

LIEBERMAN, Marcia (I972): “Some day my prince will come’: Female acculturation through the fairy tales». College English núm. 34: 383-395.

LlORCA, Vicenta (20I7): La Delicada de Gandia. Gandia: Lletra Impresa Edicions.

López, Nunila (2OII): La ventafocs ja no creu en prínceps blaus. Trad. M. J. EsCRIVÀ. La Pobla Llarga: Ed. 96.

LUNDT, Bea (I999): «Die Prinzessin auf der Erbse als Quelle historischer Sozialisationsforschung». Dins Udo ARnOLD; Peter MeYers; Uta C. SCHMIDT, Sationen einer Hochschullaufbahn. Festschrift für Annette Kuhn zum 65. Geburtstag. Dortmund: Edition Ebersbach, p. 247-260.

MACDONALD, Ruth (I982):«The tale retold: feminist fairy tales». Children's literature assotiation quarterly núm. 7: I8-20.

MARTí, Josep (I996): El Folklorismo: uso y abuso de la tradición. Barcelona: Ronsel.

MCCALluM, Robyn (I996): «Metafictions and experimental work». Dins P. HuNT (ed.): International companion encyclopedia of children's literature. New York: Routledge, p. 397-409.

MönninghofF, Wolfgang (2005): Das grosse Hans Christian Andersen Buch. Düsseldorf: Artemis \& Winkler.

MunSCH, Robert (I980): The paper bag princess. Il. Michael MARTCHENKO. Buffalo: Annick Press.

NorA, Pierre (I988): «Memoria colectiva». Dins J. Le GofF; R. ChARTIER; J. Revel (dirs.): La nueva historia. Bilbao: Mensajero, p. 454-458.

ORIOL, Carme (2OI3): «L'estudi de la literatura popular catalana des d'una perspectiva de gènere». Dins M. BACARDí (coord.): La literatura catalana contempo- 
«La princesa i el pèsol» (ATU 704): de les reescriptures escolars a la construcció...

rània: intertextos, influències i relacions. Barcelona: Institut d'Estudis Catalans (Societat Catalana de Llengua i literatura) / Universitat Autònoma de Barcelona, p. I97-209.

PÉrez, Javier; José Luis AlCAIDE (20I5): Antonio Fillol Granell (I870-I930): naturalismo radical y modernismo. València: Ajuntament de València.

PUIG, Irene de (2005) «La princesa i el pèsol». GrupIREF. Disponible a: <http:// www.grupiref.org/documents/la-princesa-i-el-pesol.pdf> [data de consulta: abril de 20I8].

ROBERTSON, Roland (I992): Globalization: social theory and global culture. London: Sage Publications.

RODARI, Gianni (I973): Grammatica della fantasia: introduzione all'arte di inventare storie. Torino: Giulio Einaudi.

RuIz, Carmen (20I3): «Enfocando las relaciones amorosas en la adolescencia. La necesidad de impulsar nuevos modelos». Convives núm. 5: I6-24.

SANTOLÀria, Alícia (2OI5): «Las otras protagonistas de la rondallística catalana: modelos para adaptar y enseñar». Revista de lenguas y literaturas catalana, gallega y vasca núm. 20: 223-24I.

SCHNEller, Cristian (I867): «Die Empfindlichste (La più delicata)». Märchen und Sagen aus Wälschtirol. Innsbruck: Verlag der Wagner'schen UniversitätsBuchhandlung, 45, p. I28-29.

SCIESZKA, Jon (I992): The stinky cheese man and other fairly stupid tales. Il-1. Lane SMITH London: Puffin.

SHOJAEI KAWAN, Christine (2005): «The princess on the pea: Andersen, Grimm and the Orient». Fabula núm. 46 (I/2): 89-II5.

STEIG, William (20I3): Shrek! Trad. Elena del AMO. Barcelona: Libro del Zorro Rojo.

TATAR, Maria (I993): Of with their heads! Fairy tales and the culture of childhood. Princeton: Princeton University.

- (2004): «La princesa y el guisante». Dins Los cuentos de hadas clásicos anotados. Trad. Luis NoriegA. Barcelona: Crítica, p. 298-30I.

- (2008): The annotated Hans Christian Andersen. New York: W. W. Norton \& Company.

TIFFIN, Jessica (2009): Marvelous geometry: narrative and metafiction in modern fairy tale. Detroit: Wayne State University Press.

Tucker, Nicholas (198I): The child and the book. A psychological and literary exploration. Cambridge: Cambridge University Press.

UTHER, Hans-Jörg (2004) [ATU]: The types of international folktales. A classification and bibliography, 3 vols. Helsinki: Suomalainen Tiedeakatemia.

- (2008): Handbuch zu den "Kinder- und Hausmärchen" der Brüder Grimm: Entstehung-Wirkung-Interpretation. Berlin: Walter de Gruyter.

VidAL y Micó, Francisco (I735): Historia de la portentosa vida, y milagros del valenciano apostol de Europa S. Vicente Ferrer. València: Joseph Estevan Dolz.

Wullschlager, Jackie (200o): Hans Christian Andersen: The life of a storyteller. Chicago: University of Chicago Press. 
ZIPES, Jack (I995): «Breaking the Disney spell». Dins Elizabeth BELL; Lynda HAAS; Laura SELLS (eds.): From mouse to mermaid: the politics of film, gender, and culture. Bloomington: Indiana University Press, p. 2I-42.

- (2000): «Introduction: towards a definition of the literary fairy tale». Dins J. ZIPES (ed.): The Oxford companion to fairy tales. Oxford: Oxford University Press, p. XV-XXXII.

- (2005): Hans Christian Andersen. New York: Routledge.

- (2009): Relentless progress: the reconfiguration of children's literature, fairy tales, and storytelling. New York: Routledge. 